\title{
Pengenalan Video Test Kit Kadmium Sebagai Media Pembelajaran Kimia bagi Guru SMK Negeri 7 Malang
}

\section{Introduction of Video of Test Kit Cadmium as a Chemistry Learning Media for Teachers of Publics Vocational High School 7 Malang}

\author{
Zuri Rismiarti \\ Prodi Diploma Analisis Farmasi dan Makanan, Jurusan Gizi, Poltekkes Kemenkes Malang \\ Jl. Besar Ijen No.77 C Malang \\ *Email: zurirismiarti@gmail.com
}

\begin{abstract}
Abstrak
Kegiatan Pengabdian kepada Masyarakat ini dilaksanakan di SMK Negeri 7 Malang. Kegiatan ini dilaksanakan untuk memberikan kontribusi kepada mitra dalam rangka pengembangan kualitas pendidikan dan pengajaran praktikum. Tujuan dari kegiatan pengabdian ini adalah untuk mengenalkan media pembelajaran kimia menggunakan video tutorial tentang penggunaan test kit kadmium yang menarik bagi guru SMK Negeri 7 Malang, memanfaatkan teknologi multimedia berbasis aplikasi powtoon dalam proses pembelajaran praktikum bagi guru SMK Negeri 7 Malang, meningkatkan minat dan ketrampilan para siswa SMK Negeri 7 Malang pada praktkum kimia analisis. Kegiatan ini dilaksanakan dengan melibatkan guru Kimia SMK Negeri 7 Malang. Luaran yang dihasilkan dari kegiatan ini adalah media pembelajaran praktek kimia analisis dalam bentuk video tutorial test kit kadmium yang berisi tentang bahaya kadmium, cara penggunaan test kit berbasis aplikasi powtoon.
\end{abstract}

Kata kunci: Kadmium, testkit, kimia, video

\begin{abstract}
The Community Service Activity was held at Public Vocational High School 7 Malang (SMKN 7 Malang). This activity is carried out to contribute to mitra in order to develop the quality of education and teaching practice. The purpose of this service is to introduce chemistry learning media using tutorial videos with using an attractive cadmium test kit for teachers of Public Vocational High School 7 Malang, utilizing powtoon-based multimedia technology in the practical learning process for teachers of Vocational High School 7 Malang, increasing the interests and skills for students of Vocational High School 7 Malang in analytical chemistry practice. This activity was carried out by involving chemistry teachers from SMKN 7 Malang. The output generated from this activity is a analysis chemistry practice media with tutorial video of cadmium test kit that contains the dangers of cadmium, how to use the test kit-based on powtoon aplication.
\end{abstract}

Key words: Cadmium, testkit, chemistry, video

\section{PENDAHULUAN}

Pembangunan Nasional Indonesia bertujuan agar terciptanya kualitas manusia Indonesian yang maju dan mandiri. Sasarannya adalah meningkatkan kemampuan penguasaan, pemanfaatan serta pengembangan ilmu pengetahuan dan teknologi (IPTEK). Dilaksanakan terutama melalui peningkatan alih teknologi yang didukung oleh pengembangan kemampuan 
sumber daya manusia (SDM), sarana dan prasarana penelitian yang memadai serta peningkatan mutu pendidikan, agar terwujud suatu masyarakat Indonesia yang maju, mandiri dan sejahtera. Hal ini diperlukan karena Indonesia harus sudah siap bersaing secara global dengan negaranegara lain.

Salah satu alternatif pemecahan masalah peningkatan daya saing industri nasional serta untuk merangsang penemuan-penemuan baru yang berguna untuk meningkatkan kesejahteraan bangsa, adalah adanya sumber daya manusia yang mempunyai kemampuan mengembangkan ilmu pengetahuan dan teknologi (IPTEK) di bidang ilmu kimia. Dalam rangka mempersiapkan sumber daya manusia yang berkualitas, dilaksanakan melalui pendidikan dan pelatihan semenjak dalam pendidikan tingkat menengah, dengan menyediakan sarana dan prasarana penelitian (Laboratorium) untuk menerapkan IPTEK. Peralatan sederhana seperti test kit merupakan peralatan yang mudah ditemui di pasaran pada masa sekarang ini. Test kit merupakan suatu alat yang dapat digunakan untuk mendeteksi kadar suatu senyawa bersifat kualitatif maupun kuantitatif dengan cukup akurat yang mudah digunakan dan dioperasikan oleh berbagai kalangan.

Mata pelajaran kimia merupakan salah satu mata pelajaran yang sulit dipahami oleh siswa SMAdan SMK. Hasil survey tahun 2007 sekitar 30\% siswa masih merasa kesulitan dalam memahami kimia. Untuk mempermudah pemahaman mata pelajaran kimia di SMA maupun SMK Kimia diperlukan peragaan yang sederhana, untuk melakukan praktikum kimia, media pembelajaran yang menarik dan dapat memberikan afirmasi positif kepada siswa didik untuk lebih memahami dan memantapkan teori kimia yang diajarkan.

SMK N 7 Malang merupakan satusatunya sekolah menengah kejuruan di Kota Malang yang memiliki jurusan kimia analisis dan APL (Analisis Pengujian Lab). Mitra memiliki laboratorium kimia sejumlah 3 buah. Pada tahap pengembangan teknologi sederhana seperti test kit guna menunjang pembelajaran dan praktikum pada mata pelajaran Analisis Kimia, Analisis Bahan Anorganik dan Kimia Analitik Terapan. Untuk menarik perhatian siswa didik dalam praktikum kimia analisis berupa test kit, diperlukan video tutorial yang menarik dengan animasi. Video ini berisikan latar belakang senyawa yang akan dianalisis, bahaya dari senyawa tersebut, dan cara penggunaan test kit. Kemudian video ini disajikan sebelum praktikum dimulai untuk memberikan afirmasi semangat praktek yang menyenangkan, mudah dan sederhana kepada siswa didik sehingga peserta praktek dapat termotivasi memahami teori dan membantu siswa terampil praktek di laboratorium kimia.

Untuk mengatasi hal tersebut, tim pengabdi masyarakat mengenalkan suatu media pembelajaran kimia yang ditujukan kepada guru kimia SMKN 7 Malang. Guru kimia SMK Kimia sebagai ujung tombak pelaksana pendidikan yang menyebarluaskan ilmu pengetahuan kimia di SMK, dan merupakan salah satu faktor penentu kualitas SDM Indonesia. Pengenalan test kit kadmium disajikan dengan menggunakan video tutorial test kit kadmium yang efektif, menarik, banyak animasi, melalui aplikasi powtoon.

"Powtoon" merupakan layanan online untuk membuat sebuah paparan yang memiliki fitur animasi sangat menarik diantaranya animasi tulisan tangan, animasi kartun, dan efek transisi yang lebih hidup serta pengaturan time line yang sangat mudah. Hampir semua fitur dapat diakses dalam satu layar membuat "PowToon" mudah digunakan dalam proses pembuatan sebuah paparan. Paparan yang memiliki built-in karakter kartun, model animasi dan benda benda kartun lainnya membuat layanan ini sangat cocok digunakan untuk membuat media ajar khususnya untuk para pelajar yang suka dengan suasana santai dan non formal dalam pembelajaran di kelas 
Powtoon

Manfaat Media Pembelajaran

1. Memperjelas penyajian pesan agar tidak terlalu bersifat verbalistis (dalam bentuk kata-kata tertulis atau lisan belaka).

2. Mengatasi keterbatasan ruang, waktu dan daya indera, seperti misalnya: Objek yang terlalu besar, bisa digantikan dengan realita, gambar, film bingkai, film, atau model; Objek yang kecil-dibantu dengan proyektor mikro, film bingkai, film, atau gambar.

3. Gerak yang terlalu lambat atau terlalu cepat, dapat dibantu dengan timelapse atau high-speed photography; objek yang terlalu kompleks (misalnya mesin-mesin) dapat disajikan dengan model, diagram, dan lain-lain, dan konsep yang terlalu luas (gunung berapi, gempa bumi, iklim, dan lain-lain) dapat di visualkan dalam bentuk film, film bingkai, gambar, dan lain-lain.

Penggunaan media pendidikan secara tepat dan bervariasi dapat mengatasi sikap pasif anak, menimbulkan kegairahan belajar; memungkinkan interaksi yang lebih langsung antara anak didik dengan lingkungan dan kenyataan; memungkinkan anak didik belajar sendiri-sendiri menurut kemampuan dan minatnya, memberikan perangsang yang sama. Tujuan-tujuan penggunaan bahan ajar multimedia interaktif secara garis besar dapat dipahami sebagai usaha untuk menyajikan materi yang akan dibelajarkan ke dalam format yang lebih efektif dan efisien untuk digunakan dan dimengerti. Pengembangan bahan ajar dilakukan dalam rangka memudahkan siswa untuk mengikuti proses belajar mengajar sehingga penyerapan materi dapat dilakukan dengan sempurna (Budi, 2017; Mardiyono, 2018).

Penggunaan ilmu pengetahuan dan teknologi dalam pendidikan mendorong manusia dalam beralih dari pembelajaran yang dianggap konvensional ke arah pendidikan modern. Penggunaan teknologi memberi dampak perubahan penggunaan model pembelajaran konvensional dengan tatap muka menuju pembelajaran yang berbasis komputer. Multimedia interaktif dalam penggunaan bahan ajar dalam proses pembelajaran dapat meningkatkan keinginan dan minat yang baru, membangkitkan motivasi dan rangsangan kegiatan belajar, dan bahkan membawa pengaruh-pengaruh psikologis terhadap siswa. Pemanfaatan teknologi multimedia juga bisa dilakukan dalam pengembangan bahan ajar yang dapat meningkatkan minat siswa terhadap suatu materi ajar yang disampaikan oleh guru (Supardi, 2014).

Di dalam setiap media pembelajaran pasti mempunyai kekurangan dan kelebihan, adapun kekurangan dan kelebihan media pembelajaran Powtoon sebagai jenis media pembelajaran Audiovisual. Kekurangan media pembelajaran ini adalah ketergantungan pada ketersedian dukungan sarana teknologi karena harus online; harus disesuaikan dengan system dan kondisi yang ada (harus tersedia jaringan internet dan beberapa template harus berbayar); mengurangi kreativitas dan invasi dari jenis media pembelajaran lainnya: membutuhkan dukungan SDM yang prefesional untuk mengoprasikannya. Sedangkan kelebihan media pembelajaran powtoon adalah interaktif; lebih menarik dan variatif karena banyak pilihan animasi: penggunaannya praktis.

\section{SOLUSI/TEKNOLOGI}

Pelaksanaan kegiatan pengenalan teknologi multimedia powtoon sebagai media pembelajaran kimia bagi guru SMK N 7 Malang adalah sebagai berikut:

A. Studi Pendahuluan

Tahap awal adalah dilakukan studi pendahuluan (preliminary studi) melalui wawancara (interview) dan observasi (observation). Wawancara dilakukan dengan guru kimia yang berkaitan dengan mata pelajara kimia analisis dan Kepala Sekolah SMK Negeri 7 Malang. Kegiatan studi pendahuluan tersebut dilaksanakan untuk memperoleh data tentang kondisi sekolah secara umum, kebutuhan siswa, 
proses pembelajaran, serta media yang dipergunakan dan yang dibutuhkan dalam proses pembelajaran, Observasi dilakukan untuk memperoleh data tentang jumlah laboratorium, sarana dan prasarana, kurikulum, dan media pembelajaran yang dipergunakan dalam proses pembelajaran maupun praktikum.

Studi pendahuluan ini dilakukan agar kegiatan pengabdian kepada masyarakat untuk mengetahui sarana dan prasarana yang sudah ada serta metode pembelajaran yang sudah dilakuakan. Disamping itu untuk mengetahui penguasaan teknologi multimedia yang dimiliki para guru sehingga bisa menentukan materi pengenalan media pembelajaran yang presisi. Selain itu, dapat memberi kontribusi dalam meningkatkan pengayakan media pembelajaran kimia bagi guru-guru kimia dan mampu mentransfer ilmu kepada peserta didik melalui teknologi multimedia.

B. Penyediaan Peralatan Pendukung

Peralatan yang digunakan dalam pengenalan teknologi multimedia powtoon sangat diperlukan. Untuk membuat video menggunakan powtoon, harus tersedia laptop, jaringan internet, pembuat harus memiliki akun powtoon sehingga harus regristrasi terlebih dahulu dan akun youtube untuk mengunduh video yang tekah dibuat. Untuk disajikan video tutorial dari powtoon kepada guru kimia di SMKN 7 Malang memerlukan LCD proyektor dan audio.

C. Pelatihan SDM daan Pembuatan Video Tutorial Test Kit Melalui Powtoon

Sumber daya manusia yang digunakan untuk membuat video tutorial test kit kadmium ini melibatkan dosen dan mahasiswa. Dosen bertindak sebagai pembimbing, ide konten untuk video. Mahasiswa Anafarma (Analisis Farmasi dan Makanan) Poltekkes Kemenkes Malang berperan sebagai pembuat, penyalur kreatifitas dari dosen pembimbing. Proses pembuatan ini dengan tema testkit cadmium, yang merupakan teknologi penapisan telah dikembangkan di prodi Anafarma Poltekkes Kemenkes Malang. Test kit cadmium ini juga sangat relevan jika diberikan ke peserta didik SMK Negeri 7 Malang karena materi ini dapat diberikan sebelum praktikum kimia analisis dimulai.

Teknologi multimedia powtoon menghasilkan video animasi yang sangat menarik dengan durasi yang singkat sehingga siswa dapat dengan mudah menagkap isi materi dan tidak terlalu lama. Hasil dari video ini berdurasi sekitar 6 menit.

Video ini juga menampilkan bahaya dari senyawa cadmium, sumber pencemar cadmium, penggunaan cadmium dalam kehidupan sehari-hari, dan tahapan penggunaan test kit cadmium. Video ini juga dilengkapi dengan suara dan warnawarna yang menarik untuk anak remaja.

Langkah yang terakhir adalah dalam pembuatan video tutorial ini adalah mengkopi video ke dalam Compact Disk (CD). Langkah ini dilakukan dengan menggunakan Nero Software. Video tersebut pada akhirnya diserahkan ke SMK Negeri 7 Malang sebagai mitra kegiatan pengabdian ini dan selanjutnya akan digunakan sebagai media dalam proses pembelajaran yang ada di sekolah tersebut.

D. Pengenalan Media Pembelajaran dengan Powtoon bagi guru-guru Kimia SMKN 7 Malang

Tahapan terakhir pada program pengabdian pada masyarakat ini adalah pengenalan media pembelajaran powtoon bagi para guru kimia d SMKN 7 Malang yang berjumlah 10 orang. Video ini dibuat dengan aplikasi powtoon menggunakan internet untuk mengakses aplikasi tersebut selama proses pembuatan. Kemudian video tersebut diperoleh dengan cara mengunduh di youtube (link video telah dikirimkan melalui email dari aplikasi powtoon). Proses pembuatan dilakukan oleh dosen dan mahasiswa anafarma Poltekkes Kemenkes Malang. Kontribusi mitra pada kegiatan ini ditunjukkan dengan menyediakan salah satu peralatan pendukung yaitu LCD proyektor 
dan audio, serta ruangan laboratorium sebagai tempat lokasi kegiatan pengabdian masyarakat. Mitra juga terlibat aktif dalam memberikan masukan dan saran terkait pelaksanaan kegiatan agar program pengabdian masyarakat ini berjalan dengan lancar. Disamping itu para guru bersedia untuk mengikuti pengenalan video test kit cadmium sebaga media pembelajaran praktikum berbasis multimedia untuk bisa diterapkan di lingkungan sekolah. Selanjutnya guru-guru kimia SMKN 7 Malang dapat mengenalkan video test kit kadmium kepada siswa-siswi SMK N 7 Malang sebelum proses praktikum mata kuliah kimia analitik. Selain konten penggunaan testkit cadmium, video ini juga memberian informasi tentang bahaya cadmium bagu kesehatan, dampak yang ditimbulkan bagi lingkungan, kegunaan/aplikasi logam cadmium dalam kehidupan sehari-hari. Materi-materi tersebut juga sangat relevan untuk siswa SMK N 7 Malang pada mata kuliah Analisis Kimia, Analisis Bahan Anorganik dan Kimia Analitik Terapan. Luaran yang dihasilkan pada program ini juga diperolehnya sertifikat HAKI (Hak Kekayaan Intelektual).

\section{HASIL DAN DISKUSI}

Model program yang dilaksanakan pada kegiatan ini terdiri dari beberapa komponen/unsur seperti peralatan (LCD, laptop, CD, aplikasi powtoon), materi pengabdian masyarkat, para guru kimia SMKN 7 Malang sebagai mitra, dosen dan mahasiswa Anafarma Poltekkes Kemenkes Malang sebagai tim pengabdian masyarakat. Gambaran dari model yang diterapkan pada kegiatan ini diperlihatkan pada Gambar 1..

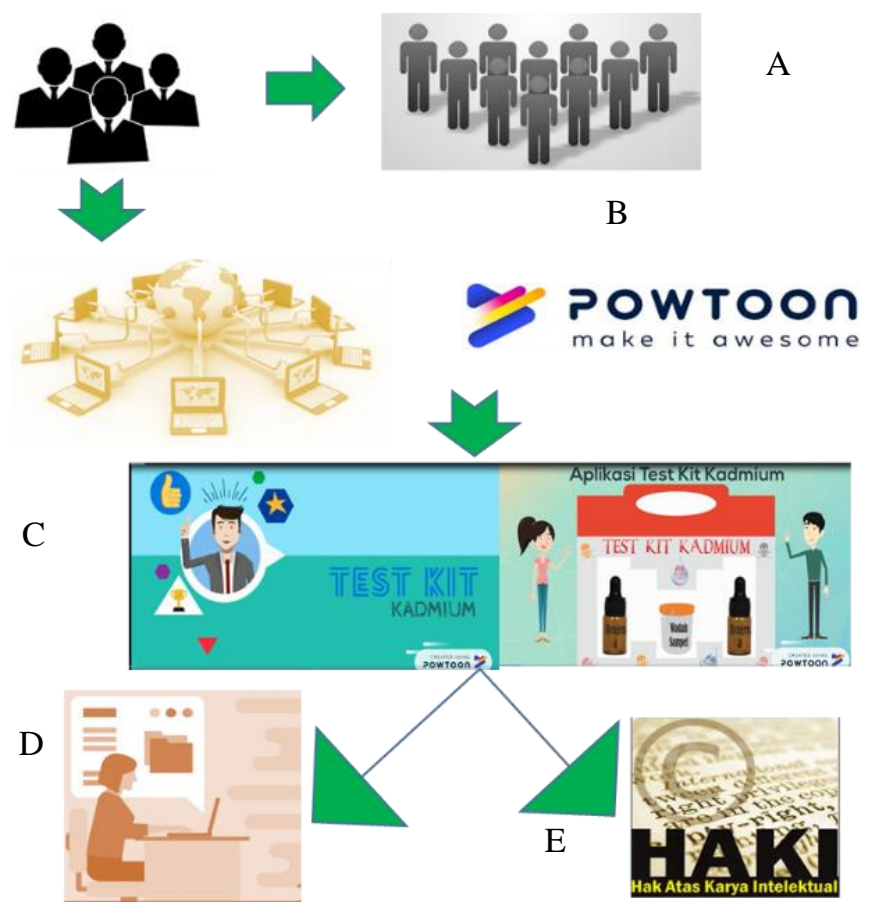

Gambar 1. Tahapan pelaksanaan Pengenalan Video Test Kit Kadmium Bagi Guru-Guru SMKN 7 Malang

Gambar 1 merupakan tahapan pelaksanaan program pengabdian pada masyarakat, $\mathrm{A}=$ tim pengabdi yang terdiri dari dosen Anafarma Poltekkes Kemenkes Malang yang dibantu oleh mahasiswa memberikan materi pengabdian masyarakat dan mengenalkan video tutorial testkit kadmium berbasis powtoon sebagai media pembelajaran kimia. B merupakan tahapan proses pembuatan video testkit cadmium menggunakan aplikasi powtoon, pada tahap ini dilakukan oleh dosen dan mahasiswa. C adalah video testkit cadmium yang telah dibuat dan siap disajikan kepada guru SMKN 7 Malang. Video ini berdurasi 6 menit dengan warna yang menarik, banyak animasi kartun sangat sesuai dengan kkarakter remaja. D merupakan proses transfer ilmu dari para guru kimia SMKN 7 Malang kepada siswa dengan menggunakan video tutorial SMKN 7 Maang sebagai media pembelajaran kimia. Metode ini dilakukan sebelum praktikum dimulai. Desain dari video sangat bervariatif dilengkapi audio dan disajikan dengan animasi kartun sehingga membuat siswa 
sebagai peserta didik merasa semangat, termotivasi untuk menyimak materi tentang cadmium, dan cara penggunaan test kit cadmium. E merupakan output yang dihasilkan dari program pengabdian masyarakat ini yaitu pengajuan HAKI hingga diperoleh sertifikat sehingga video yang telah dibuat telah mempunyai hak cipta.

Gambar 2 memperlihatkan model program pengenalan video test kit kadmium sebagai media pembelajaran kimia bagi guru SMK Negeri 7 Malang. Materi pengabdian masyarakat initerdiri dari 6 sesi yang ditunjukkan pada Gambar 2. Sesi pertama meliputi pengenalan prodi Diploma Anafarma Poltekkes Kemenkes Malang, profil prodi, visi dan misi serta prospek kerja. Pengenalan prodi disampaikan oleh Ketua Prodi. Sesi kedua dengan materi adalah logam berat tentang definisi; jenis-jenis logam berat yang berbahaya; kegunaan logam berat dalam kehidupan sehari-hari; sumber pencemar logam berat; dampak yang ditimbulkan bagi lingkungan, kesehatan manusia, biota laut, tumbuhan, yang mempengaruhi rantai makanan; regulasi ambang batas logam berat yang diterapkan oleh Pemerintah di air dan makanan; pengamamanan untuk logam berat; tips waspada paparan logam berat.

Sesi ketiga dengan materi adalah pengenalan instrumentasi yang digunakan untuk menganalisis logam berat yang meliputi Atomic Absorption Spectrofotometry (AAS); Flame Atomic Absorption Spectrofotometry (FAAS); Graphite Furnace Atomic Absorption Spectroscopy (GFAAS); Hydride Generation Atomic Adsorption Spectroscopy (HGAAS); Cold Vapour Atomic Adsorption Spectroscopy (CVAAS); Inductively Coupled Plasma Optical Emission Spectrometry (ICP-OES); Inductively Coupled Plasma Mass Spectrometry (ICP-MS); UV-Visible Spectrofotometric (UV-Vis). Materi instrumentasi tersebut dipaparkan oeh dosen anafarma dengan menunjukkan karakteristik dari masing-masing instrumentasi tersebut. Sesi keempat adalah pengenalan tentang penapisan teknologi sederhana, yaitu test kit. Test kit telah banyak digunakan dalam laboratorium seperti kertas indicator $\mathrm{pH}$, kertas lakmus. Pada sesi ini dijelaskan tentang definisi, jenis-jenis test kit, contoh test kit yang ada di pasaran, cara menggunakan test kit. Sesikelima merupakan pengenalan testkit kadmium yang merupakan pengembangan penelitian dari dosen anafarma. Sesi ini dijelaskan optimasi parameter yang telah dilakukan dalam penelitian sehingga dihasilkan testkit cadmium yang dapat mendeteksi sampel yang mengandung cadmium. Pada Gambar 2 terilhat guruguru kimia SMKN 7 Malang sangat antusias untuk mendengarkan, menyimak, berbagi pengalaman tentang kegiatan ini.
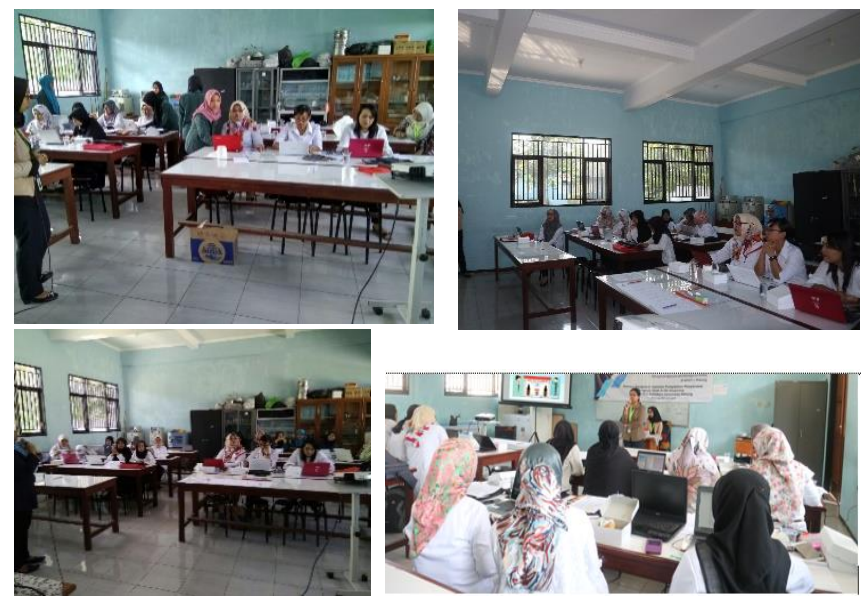

Gambar 2. Pelaksanaan program pengabdian pada masyarakat di SMKN 7 Malang

Sesi terakhir merupakan pengenalan video testkit cadmium dengan menggunakan aplikasi powtoon. Video ini merupakan rangkuman dari materi pada sesi ke-1 hingga ke-5 yang ditampilkan dengan animasi melalui aplikasi powtoon yang disertai dengan musik. Video ini disajikan menarik yang membuat siswa-siswa SMK pada usi remaja termotivasi untuk belajar materi tersebut. Video ini dapat ditampilkan di ruang laboratorium sebelum praktikum dimulai untuk menimbulkan rangsangan 
semngat praktikum sehingga moomok praktikum kimia yang menakutkan, sulit dapat dihilangkan dari pikiran siswa. Akibatnya mereka dapat termotivasi untuk belajar dan praktikum dengan terampil karena afirmasi semngat yang diberikan dari video tutorial yang telah merea tonton. Tampilan video testkit cadmium disajikan pada Gambar 3.

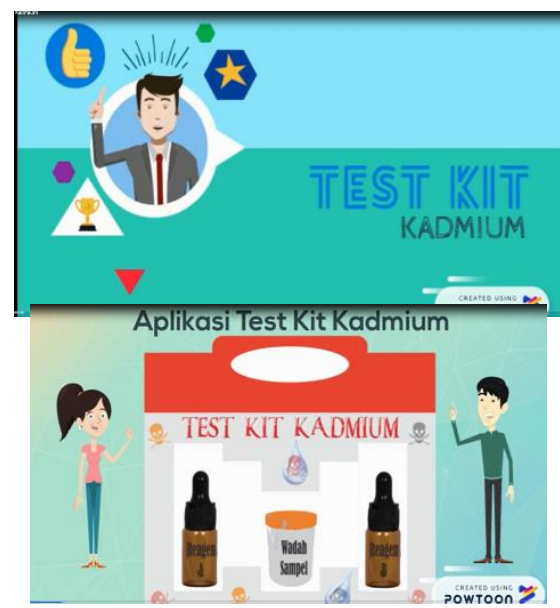

Gambar 3. Tampilan Video Test Kit Kadmium

Hasil pengabdian masyarakat ini akan dipublikasikan ke dalam seminar nasional, dalam pubilkasi junal dan video testkit kadmium dalam proses pengajuan untuk memperoleh sertifikat HAKI tahun 2019.

Evaluasi kegiatan ini dilakukan dengan keberhasilan para guru memahami materi-materi yang telah disampaikan dari pembicara, adanya animo keaktifan peserta dalam mengikuti rangkaian kegiatan selama berlangsung dari sesi pertama hingga keenam. Keberlanjutan program diteruskan para guru SMKN 7 Malang juga akan merencanakan menerapkan video pembelajaran testkit kadmium di kelas maupun di ruang laboratorium yang ditampilkan sebelum praktikum kimia analitik kimia terapan pada siswa kelas XI dan XII.

\section{KESIMPULAN}

Pengenalan video testkit kadmium dengan aplikasi powtoon bagi guru SMKN 7 Malang dapat disimpulkan bahwa pengembangan media pembelajaran maupun praktikum kimia yang menarik bagi siswa di SMK dapat berupa video tutorial yang berkaitan dengan topik sesuai dengan bidang keilmuan peserta didik. Pengenalan ini ditujukan ke guru karena sebagai ujung tombak transfer ilmu ke siswa. Video tutorial yang ditampilkan berupa animasi kartun, warna yang bervariatif disertai musik dapat membuat siswa termotivasi sehingga momok praktikum kimia yang sulit, mengangkan dapat dihilangkan dari pikiran mereka.

Materi logam berat yang mencakup definisi, dampak yang ditimbulkan bagi kesehatan dan lingkungan, sumber pencemar, regulasi ambang batas, pengamanan dan tips terhindar dari logam berat; instrumentasi untuk analisis logam berat; pengenalan test kit juga perlu diberikan pada guru-guru kimia SMK sebagai brainstorming dan manajemen pengetahuan (updating knowledge). Selain itu, kedua mitra dapat menjalin dan memelihara kerjasama yang baik sehingga dapat memberikan kontribusi yang nyata dalam pengembangan pendidikan sebagai salah satu pelaksanaan Tri Dharma Perguruan Tinggi.

\section{UCAPAN TERIMA KASIH}

Penulis mengucapkan terima kasih kepada Politeknik Kesehatan Kemenkes Malang atas pembiayaan kegiatan ini melalui hibah pengabdian kepada masyarakat TA.2018 dan SMKN 7 Malang sebagai mitra kegiatan dalam pengenalan video tutorial test kit cadmium sebagai media pembelajaran kimia.

\section{PUSTAKA}

Budi, A.S, 2017, Pembuatan Video Tutorial Table Manner Sebagai Media Pembelajaran Bahasa Inggris Untuk 
Siswa SMK Negeri 3 Jember, Jurnal Pengabdian Masyarakat JDINAMIKA, 2 (1), 22-26

Hambali, M., F. Mayasari, F.Noermansyah, 2014, Ekstraksi Antosianin Dari Ubi Jalar Dengan Variasi Konsentrasi Solven, Dan Lama Waktu Ekstraksi, Teknik Kimia No. 2, Vol. 20, 25-35

Mardiyono, 2018, Teknologi Multimedia
Untuk Pembuatan Bahan Ajaar Pada Guru SMPIT Bina Insani 1 Semarang, Jurnal Pengabdian Masyarakat JDINAMIKA, 23(1), 45-50

Supardi, A, 2014, Penggunaan Multimedia Interaktif Sebagai Bahan Ajar Suplemen Dalam Peningkatan Minat Belajar, Jurnal Ilmiah Pendidikan Dasar, 1 (2), 161-167 